\title{
Covid-19 Presenting as Acute Limb Ischemia
}

\author{
Balraj Singh ${ }^{1}$, Parminder Kaur ${ }^{2}$, Nora Ajdir ${ }^{3}$, Sachin Gupta ${ }^{4}$, Michael Maroules ${ }^{1}$ \\ 1. Hematology/Oncology, Saint Joseph's University Medical Center, Paterson, USA 2. Cardiology, Saint Joseph's \\ University Medical Center, Paterson, USA 3. Internal Medicine, Saint Joseph's University Medical Center, Paterson, \\ USA 4. Internal Medicine, Reading Hospital, West Reading, USA
}

Corresponding author: Balraj Singh, bsriar9@gmail.com

\begin{abstract}
Coronavirus disease-2019 (COVID-19) is caused by severe acute respiratory syndrome coronavirus 2 (SARSCoV-2) and represents a potentially fatal disease. COVID-19 is associated with a hypercoagulable state leading to increased incidence of venous thromboembolism. Arterial thrombosis has been reported, but the prevalence is not known. Herein, we report an unusual presentation of a 77-year-old male who presented with dyspnea and pain in left leg and was found to have acute limb ischemia. Our case adds to the limited literature regarding arterial thrombosis in COVID-19.
\end{abstract}

Categories: Internal Medicine, Oncology, Hematology

Keywords: covid-19, acute limb ischemia, arterial thrombosis, thrombosis, sars-cov-2 (severe acute respiratory syndrome coronavirus 2

\section{Introduction}

At the end of 2019, a novel coronavirus was identified as the cause of a cluster of pneumonia cases in Wuhan, a city in the Hubei Province of China. On March 11, 2020, WHO declared coronavirus disease 2019 (COVID-19) as pandemic [1]. Droplets and contact are the main means of transmission [2]. Patients with severe acute respiratory syndrome coronavirus 2 (SARS-CoV-2) infection mainly present with upper and lower respiratory tract symptoms, with complications related to cytokine storm syndrome and acute respiratory distress syndrome (ARDS) [3]. We report an unusual presentation of a 77-year-old male who presented with dyspnea and pain, swelling in the left leg, and was found to have acute limb ischemia (ALI).

\section{Case Presentation}

A 77-year-old male patient presented to emergency department with complaints of shortness of breath and pain, discoloration, and swelling of the left leg. Vital signs on presentation were heart rate 110 per minute, blood pressure $155 / 85 \mathrm{mmHg}$, oxygen saturation $96 \%$ on room air, and temperature 36 degree Celsius. The patient had bilateral crackles on lung exam and absent left dorsalis pedis and posterior tibial pulses and foot was swollen, discolored, and cold. Electrocardiogram showed sinus tachycardia 110 per minute.

Received 05/18/2020

Review began 07/14/2020 Review ended 07/15/2020 Published 07/22/2020

(c) Copyright 2020 Singh et al. This is an open access article distributed under the terms of the Creative Commons Attribution License CC-BY 4.0., which permits unrestricted use, distribution, and reproduction in any medium, provided the original author and source are credited.
On initial laboratory evaluation, the following values were noted: hemoglobin $12.1 \mathrm{~g} / \mathrm{dl}$ (reference: $12-16$ $\mathrm{g} / \mathrm{dl}$ ), hematocrit $38.2 \%$ (reference: $36 \%-46 \%$ ), white blood cells $41 \mathrm{~K} / \mathrm{mm}^{3}$ (reference: $4.5-11 \mathrm{~K} / \mathrm{mm}^{3}$ ), platelets $534 \mathrm{~K} / \mathrm{mm}^{3}$ (reference: $140-440 \mathrm{~K} / \mathrm{mm}^{3}$ ), potassium $4.1 \mathrm{meq} / \mathrm{L}$ (reference: $3.5-5 \mathrm{meq} / \mathrm{L}$ ), glucose $126 \mathrm{mg} / \mathrm{dl}$ (reference: $70-105 \mathrm{mg} / \mathrm{dl}$ ), creatinine $0.61 \mathrm{mg} / \mathrm{dl}$ (reference: 0.6-1.30 mg/dl), blood urea nitrogen $8 \mathrm{mg} / \mathrm{dl}$ (reference: $7-23 \mathrm{mg} / \mathrm{dl}$ ), lactic acid $1.1 \mathrm{mmol} / \mathrm{L}$ (reference: $0.5-2.2 \mathrm{mmol} / \mathrm{L}$ ), troponin 0.136 $\mathrm{ng} / \mathrm{ml}$ (reference: less than $0.03 \mathrm{ng} / \mathrm{ml}$ ), D-dimer 2.77 (reference: less than 0.5 ), prothrombin time 14.8 seconds (reference: 12.2-14.9 seconds), international normalized ratio (INR) 1.2 (reference: less than 1), partial thromboplastin time 39.8 seconds (reference: 21.3-35.1 seconds), lactate dehydrogenase (LDH) 392 U/L (reference: 140-271 U/L), C-reactive protein (CRP) $301 \mathrm{mg} / \mathrm{L}$ (reference: less than $10 \mathrm{mg} / \mathrm{L}$ ), ferritin $1,396 \mathrm{ng} / \mathrm{mL}$ (reference: $12-300 \mathrm{ng} / \mathrm{ml}$ ), procalcitonin $0.60 \mathrm{ng} / \mathrm{ml}$ (reference: less than $2 \mathrm{ng} / \mathrm{ml}$ ), aspartate transaminase $134 \mathrm{U} / \mathrm{L}$ (reference: 13-39 U/L), calcium $8.5 \mathrm{mg} / \mathrm{dl}$ (reference: $8.6-10.3 \mathrm{mg} / \mathrm{dl}$ ), and albumin $2.7 \mathrm{mg} / \mathrm{dl}$ (reference: $3.5-5.0 \mathrm{mg} / \mathrm{dl}$ ). Chest X ray showed bilateral hazy infiltrates. CT angiography of the abdomen and aorta with Iliofemoral runoff showed thrombus within the mid left superficial femoral artery and occluded left anterior tibial artery, left posterior tibial artery, and left peroneal artery with no flow to the foot (Figure 1). 


\section{Cureus}

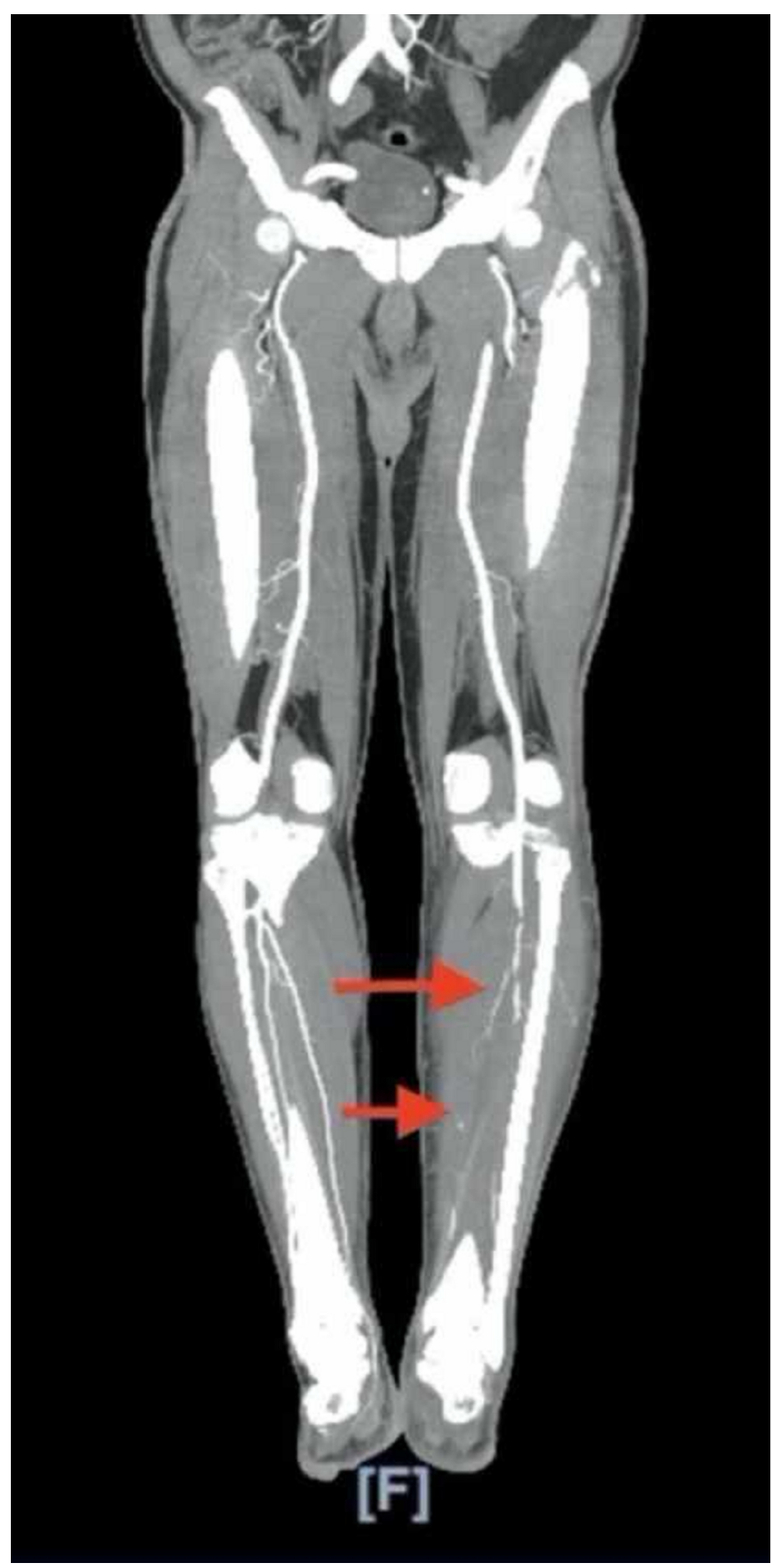

FIGURE 1: CT angiography of aorta with iliofemoral runoff showing occluded left anterior tibial artery and left peroneal artery.

Covid-19 was diagnosed on the basis of reverse transcription polymerase chain reaction (RT-PCR) testing. Echocardiogram showed an ejection fraction of $60 \%$. The patient was placed on air-borne precautions and was started on ceftriaxone, azithromycin, hydroxychloroquine, and therapeutic anticoagulation with heparin. He underwent thrombectomy of left common femoral artery, profunda femoris, superficial femoral artery, popliteal artery, anterior tibial artery, posterior tibial artery, and peroneal artery.

\section{Discussion}

The clinical spectrum of COVID19 continues to evolve. The most common symptoms being reported are fever, myalgia, cough, and dyspnea, and less frequently headache, diarrhea, nausea,

and vomiting [4]. Severity of infection could be varied from asymptomatic infection to critical disease. Smell 
and taste disorders (e.g., anosmia and dysgeusia) have also been reported as common symptoms in patients with COVID-19 [5]. Although in COVID-19 respiratory symptoms predominate, thrombosis can occur with COVID-19 [6]. Among patients with advanced age and medical comorbidities (cardiovascular disease, diabetes mellitus, hypertension, chronic lung disease, cancer, chronic kidney disease, obesity, and smoking), COVID-19 is frequently severe [7].

Patients with severe COVID-19 infection can develop a disseminated coagulopathy characterized by increases in procoagulant factors like fibrinogen and D-dimer leading to widespread microvascular thrombosis. This state has been termed thromboinflammation or COVID-19-associated coagulopathy [8]. Bellosta et al. evaluated 20 patients with ALI who were positive for COVID-19 and concluded that revascularization was lower than expected, which was hypothesized was due to a virus-related hypercoagulable state; however, the use of prolonged systemic heparin may improve surgical treatment efficacy as well as improve limb salvage and overall mortality [9]. Zhang et al. reported three COVID- 19 patients with cerebral infarcts. One of the patients had thrombosis in the bilateral lower limbs as well as in digits 2 and 3 of the left hand. In all the three cases, serologic tests were positive for anticardiolipin IgA antibodies as well as anti- $\beta 2$-glycoprotein IgA and IgG antibodies. Lupus anticoagulant was not detected in any of the patients. These antibodies can arise transiently in patients with critical illness and various infections [10]. In our patient, antiphospholipid antibody testing was not done.

All hospitalized patients with COVID-19 should receive pharmacologic thromboprophylaxis with low molecular weight heparin (LMWH) or fondaparinux unless bleeding risk and full therapeutic-intensity anticoagulation in the appropriate clinical scenario [11]. Anticoagulant therapy mainly with LMWH appears to be associated with better prognosis in severe COVID-19 patients meeting sepsis-induced coagulopathy criteria or with markedly elevated D-dimer [12].

\section{Conclusions}

We report an unusual presentation of a 77-year-old male patient who presented with dyspnea and acute pain in left leg and was found to have ALI and underwent thrombectomy. Our case and review of literature reveals that health care providers should be aware of this unusual life-threatening manifestation of COVID 19 so that appropriate measures can be taken for the vascular emergency.

\section{Additional Information}

\section{Disclosures}

Human subjects: Consent was obtained by all participants in this study. Conflicts of interest: In compliance with the ICMJE uniform disclosure form, all authors declare the following: Payment/services info: All authors have declared that no financial support was received from any organization for the submitted work. Financial relationships: All authors have declared that they have no financial relationships at present or within the previous three years with any organizations that might have an interest in the submitted work. Other relationships: All authors have declared that there are no other relationships or activities that could appear to have influenced the submitted work.

\section{References}

1. Velavan TP, Meyer CG: The COVID-19 epidemic. Trop Med Int Health. 2020, 25:278-280. 10.1111/tmi.13383

2. Jin Y-H, Cai L, Cheng Z-S, et al.; Zhongnan Hospital of Wuhan University Novel Coronavirus Management and Research Team, Evidence-Based Medicine Chapter of China International Exchange and Promotive Association for Medical and Health Care (CPAM): A rapid advice guideline for the diagnosis and treatment of 2019 novel coronavirus (2019-nCoV) infected pneumonia (standard version). Mil Med Res. 2020, 7:4. 10.1186/s40779-020-0233-6

3. Yi Y, Lagniton PNP, Ye S, Li E, Xu R-H: COVID- 19: what has been learned and to be learned about the novel coronavirus disease. Int J Biol Sci. 2020, 16:1753-1766. 10.7150/ijbs.45134

4. Guan WJ, Ni ZY, Hu Y, et al.: Clinical characteristics of coronavirus disease 2019 in China . N Engl J Med. 2020, 382:1708-1720. 10.1056/NEJMoa2002032

5. Lechien JR, Chiesa-Estomba CM, De Siati DR, et al.: Olfactory and gustatory dysfunctions as a clinical presentation of mild-to-moderate forms of the coronavirus disease (COVID- 19) a multicenter European study. Eur Arch Otorhinolaryngol. 2020, 277:2251-2261. 10.1007/s00405-020-05965-1

6. Kaur P, Posimreddy S, Singh B, Qaqa F, Habib HA, Maroules M, Shamoon F: COVID-19 presenting as acute limb ischaemia. Eur J Case Rep Intern Med. 2020, 7:001724. 10.12890/2020_001724

7. Driggin E, Madhavan MV, Bikdeli B, et al.: Cardiovascular considerations for patients, health care workers, and health systems during the COVID-19 pandemic. J Am Coll Cardiol. 2020, 75:2352-2371. 10.1016/j.jacc.2020.03.031

8. Connors JM, Levy JH: Thromboinflammation and the hypercoagulability of COVID-19. J Thromb Haemost. 2020, 18:1559-1561. 10.1111/jth.14849

9. Bellosta R, Luzzani L, Natalini G, et al.: Acute limb ischemia in patients with COVID-19 pneumonia [Epub ahead of print]. J Vasc Surg. 2020, 10.1016/j.jvs.2020.04.483

10. Zhang Y, Xiao M, Zhang S, et al.: Coagulopathy and antiphospholipid antibodies in patients with Covid-19. N Engl J Med. 2020, 382:e38. 10.1056/NEJMc2007575

11. Paranjpe I, Fuster V, Lala A, et al.: Association of treatment dose anticoagulation with in-hospital survival 


\section{Cureus}

among hospitalized patients with COVID-19. J Am Coll Cardiol. 2020, 76:122-124.

10.1016/j.jacc.2020.05.001

12. Tang N, Bai H, Chen X, Gong J, Li D, Sun Z: Anticoagulant treatment is associated with decreased mortality in severe coronavirus disease 2019 patients with coagulopathy. J Thromb Haemost. 2020, 18:1094-1099. 10.1111/jth.14817 